\title{
El Partido Liberal en la crisis de la Restauración
}

\author{
José María Marín Arce
}

A la breve experiencia republicana le sucede, en 1874, la Restauración Borbónica en la persona de Alfonso XII y este cambio de régimen hace necesaria la recomposición de las fuerzas políticas. Aunque el joven Rey había sido proclamado por el tradicional método de la insurrección militar, la monarquia recién instaurada tenía vocación decididamente civilista. Para que esto no fuera sólo un deseo era necesario ensanchar la base política del nuevo régimen, buscar el consenso de poder y conseguir la reconciliación entre las distintas corrientes liberales. No hubiera sido posible la estabilidad del sistema si el liberalismo, dividido en multitud de grupos y tendencias, no se hubiera unificado en torno a dos formaciones: el Partido Liberal y el Partido Conservador, y si estos partidos no hubieran llegado a los acuerdos necesarios para afianzar el régimen.

El partido conservador, de la mano de Cánovas, fue el sucesor más directo del moderantismo, y el Partido Liberal, encabezado por Sagasta, el heredero de la tradición progresista del liberalismo del siglo xIX. El acuerdo entre ambos partidos pasaba necesariamente por el consesuamiento de una norma constitucional, pero era precisamente en este tema donde mayor distancia les separaba. Sin embargo, tal diferencia no iba a ser obstáculo para que llegaran al "pacto constitucional».

Una vez concluido el proceso constituyente, conservadores y liberales van a llevar a cabo la labor de integrar en sus filas a las diversas fracciones hasta ahora independientes. Cánovas, desde el gobierno, aglutinó en torno al "partido conservador" a las dos agrupaciones que tenía a su derecha: los «moderados históricos", que hacían de su fidelidad a la Constitución de 1845 la justificación de su existencia, y «la Unión Católica», constituida por los que abandonaron las filas carlistas cuando el pretendiente se alzó en armas ${ }^{1}$.

ARtola, Miguel, Partidos y programas políticos 1808-1936, Tomo I. Madrid, Aguilar, 1977, págs. 328-329. 
La tarea más dificil fue la de Sagasta que hizo de los "constitucionales" el núcleo de un numeroso partido liberal, organizando y conduciendo a progresistas, monárquicos radicales y republicanos moderados. El proceso unificador fue largo y contradictorio, de 1875 a 1885, y pasó por todo tipo de vicisitudes, fraccionamientos y pactos hasta llegar al reagrupamiento final.

Hacia 1885, los partidos conservador y liberal habian conseguido: a) ampliar la base política del sistema de la Restauración, desde el monarquismo más conservador al republicanismo moderado; b) la aceptación de la monarquía constitucional, personificada en Alfonso XII, y c) la aquiescencia generalizada con la Constitución de 1876 y las reformas democráticas propugnadas en el programa de gobierno liberal presidido por Sagasta.

Los acuerdos programáticos en torno a la monarquía constitucional estaban dados, pero era necesario desarrollar las bases para su funcionamiento, había que organizar el sistema de partidos y los mecanismos para que liberales y conservadores pudieran alternarse en el poder. Cánovas, defensor a ultranza del bipartidismo inglés como único medio eficaz para estabilizar la monarquía parlamentaria ${ }^{2}$, aprovechó la desaparición de Alfonso XII, en noviembre de 1885, para ensayar la alternancia con el partido liberal. El jefe conservador creyó que la muerte del monarca suscitaría una rebelión republicana y carlista y que este peligro podría ser contenido más fácilmente por los liberales que por su propio partido, así, tras consultar privadamente a Sagasta y con el pretexto jurídico de que sus poderes caducaban con la muerte del Rey, aconsejó a la regente doña María Cristina de Habsburgo que designara un gobierno liberal.

Esta primera experiencia de turno pacífico entre liberales y conservadores, conseguida por el acuerdo entre Cánovas y Sagasta en la negociación conocida como el "Pacto del Pardo", no fue un arreglo secreto entre ambos dirigentes para implantar a perpetuidad la alternancia tramada entre ellos, pues el turno pacífico estaba ya implícito en la designación de Sagasta por el Rey en $1881^{3}$. El "turnismo" no fue un esquema previamente calculado entre Cánovas y Sagasta, sino el resultado de la experiencia de 1885, un ejemplo a seguir por gobiernos posteriores, que iría madurando en un proceso de permanente acuerdo entre ambos partidos.

2 González Blanco, Edmundo, Ideario de Cánovas. Madrid, Jason, 1931, págs. 199-202.

3 Carr, Raymond, España. 1808-1939, Barcelona, Ariel, 1979, pág. 347. 
Pero no bastaba sólo con el pacto entre liberales y conservadores para la alternancia en el gobierno, pues no se podía esperar que el resultado de la voluntad popular expresada en las urnas confirmara dicha alternancia. Por ello, desde 1885 se recurrió a la prerrogativa regia de nombramiento y destitución de jefes de gobierno, con el fin de “fabricar» unas nuevas Cortes en las que el partido entrante tuviera suficiente mayoría para gobernar. En esencia, el procedimiento consistía en que tras un período prudencial de permanencia en el gobierno de uno de los partidos dinásticos, solía oscilar de dos a cinco años, el Rey, haciendo uso de la regia prerrogativa, nombraba presidente del Consejo al jefe del otro partido turnante, se disolvian las Cortes y el nuevo partido, ya en el poder, preparaba las elecciones.

El bipartidismo británico, que tanta influencia ejerció sobre Cánovas, no puede ser comparado al español ni por su origen ni por su funcionamiento. Mientras que en España el bipartidismo se establece como un simple pacto que permite el turno pacífico entre liberales y conservadores, en Gran Bretaña tiene una profunda solidez basada en: a) causas históricas; b) causas financieras derivadas de lo costoso que era en Inglaterra mantener un partido; c) el sistema electoral con escrutinio nominal y mayoritario a una vuelta que elimina prácticamente a los partidos pequeños; d) la tradición de forzar, con el derecho de disolución, a que los parlamentos conserven la disciplina de partido; e) la estructura social británica, y f) incluso, como algunos afirman, la propia forma rectangular de la Cámara de los Comunes ${ }^{4}$.

Mientras cue en España la disolución de las Cámaras y la convocatoria electoral se produce después de que el monarca ha designado nuevo presidente del Consejo, en Gran Bretaña el Parlamento es disuelto muy cerca del final normal de su mandato (cinco años), permitiendo únicamente al gobierno la flexibilidad de elegir el momento más oportuno de la convocatoria electoral, normalmente en el curso del cuarto año, buscando una coyuntura favorable para el propio partido y desfavorable para la oposición. Por otra parte, es el Gabinete inglés quien formula la política y el Parlamento quien ha de aceptarla o forzar la disolución. Aun cuando excepcionalmente se gobierna en coalición, la posición del gobierno es muy fuerte y un «tercer partido" está siempre condenado a la esterilidad si no se suma dócilmente a los designios gubernamentales ${ }^{5}$. No se con-

JimÉnez de PARga, M., Los regimenes políticos contemporáneos. Madrid, Tecnos, 1983. págs. 353-355.

${ }^{5}$ Gonzalez Garcia, Teodoro, Comentarios preliminares a la obra de Jenning, Sir Ivor, El régimen Político de la Gran Bretaña. Madrid, Tecnos, 1962, pàg. XII. 
cibe tampoco en Gran Bretaña las decenas de combinaciones ministeriales que se suceden en nuestro país ni la debilidad de sus gobiernos, sometidos siempre a las presiones de sus grupos coligados.

Pero quizá la diferencia más importante que separa a ambos países es que mientras el sistema de partidos en España permaneció inmutable hasta su desaparición en 1923 y fue incapaz de integrar a otras fuerzas políticas (primero al republicanismo y más tarde, en torno a 1917, al socialismo), el bipartidismo británico supo evolucionar tratando de reflejar, lo más fielmente posible, las nuevas corrientes sociales y políticas. En este proceso, la pujanza del partido laborista, junto a la ampliación del derecho de sufragio, condujo a una reestructuración del electorado y a una reorganización de los partidos políticos, produciéndose el relevo de poder en el sistema de gobierno ${ }^{6}$.

Puesto que en España el bipartidismo conforma el marco político sobre el que se apoya el turno pacífico, debemos examinar los elementos esenciales que constituyen la infraestructura del sistema: A) el mecanismo por el cual el partido en el gobierno que convoca las elecciones, mediante la manipulación electoral logra obtener una mayoría holgada en el Parlamento y B) la composición y estructura de los partidos dinásticos, pieza básica del bipartidismo.

A) La intervención gubernamental en las elecciones se producía esencialmente por el "encasillado", un sistema por el que los dos partidos dinásticos acordaban los candidatos que se presentarían en cada una de las circunscripciones, con objeto de evitar la competencia y asegurarse, fundamentalmente mediante la aplicación del artículo 29, que saldrían elegidos diputados los que previamente se hubiera convenido.

El "encasillado" era esencialmente un pacto, pero no un pacto entre iguales, sino un pacto en el que el gobierno, por el solo hecho de serlo, tenía cierta preeminencia?. Además del gobierno, hay elementos que intervienen en este proceso y que al mismo tiempo constituyen la esencia del régimen oligárquico y caciquil. Joaquín Costa los clasifica de la siguiente manera: 1.- los "oligarcas", los llamados primates, prohombres o notables de cada bando que forman su "plana mayor", residente, de ordinario, en el centro; 2 - - los "caciques", de primero, segundo y ulterior grado, diseminados en el territorio, y 3.- el "gobernador civil" que les sirve de órgano de comunicación y de instrumento ${ }^{8}$. Este último, a las

\footnotetext{
${ }^{6}$ Stammen, Theo, Sistemas politicos actuales, Madrid, Guadarrama, 1969, pág. 63.

7 TUSELL, J., "El funcionamiento del sistema caciquil en Andalucía (1890-1931)" en Política y sociedad en la España del siglo XX. Madrid, Akal, 1978, pág. 14.

${ }^{8}$ Costa, Joaquin, Oligarquia y caciquismo. Colectivismo agrario y otros escritos. Madrid, Alianza, 1979, pág. 28
} 
órdenes del Ministro de la Gobernación, es el encargado de acoplar las candidaturas de una manera concreta y precisando para cada distrito quién será el candidato "encasillado" que cuenta con el apoyo del gobierno, o por lo menos con la aceptación del mismo.

Además del "encasillado", el gobierno utiliza otras formas de fraude electoral conocidas con el nombre genérico de «pucherazo", que van desde la violencia ejercida sobre candidatos y militantes de partidos, hasta la manipulación en las mesas electorales, la existencia de "embolados" - «micos» (personas que sustituyen a los electores) y, ya en el siglo xx, la compra de votos. A propósito de estos métodos, el joven Santiago Alba nos resume con mucho acierto los procedimientos electorales que ya se utilizaban a fines del siglo XIX:

“¿Cómo se hacen los diputados en España? se preguntaba Alba-. La primera labor es aquella: la del encasillado. Ahí es dónde se da la batalla, donde se decide el éxito, donde de cien casos, en noventa y cinco queda, como ahora se dice "descontado", el secreto de la papeleta electoral. El Gobierno "echa sus cuentas"; se adjudica una mayoría espléndida y después reparte los huecos entre las minorías. El candidato oficial, adicto o de oposición, triunfa; y si no, se le hace triunfar. ¿Cómo? iEsto lo sabemos bien todos los españoles! Mediante el clásico pucherazo, como el encasillado, glorioso invento nacional... En España estas barrabasadas del cacique tienen hasta las simpatías de las gentes, cuentan y ríen cómo el Gobernador A robó un Acta; cómo el Guardia Civil (sarcasmos de la vida) detuvo a su alcalde... ${ }^{9}$.

El caciquismo electoral no sólo se produce en la España de la Restauración. En Italia, el sistema de patronazgo era muy similar y el clientelismo y la manipulación electoral eran típicos en las provincias meridionales ${ }^{10}$. Alli tenía Giolitti sus «burgos podridos" que le aseguraban una mayoría servil a cambio de favores diversos y que le dieron un importante triunfo en las elecciones de $1913^{11}$.

Al estudiar la política inglesa desde 1867 hasta 1914 sorprende la persistencia de las viejas formas de los partidos, surgidas cuando éstos se

\footnotetext{
${ }_{9}$ Alba, Santiago, Problemas de España. Madrid, Hesperia, 1916, págs. 112-113. Se trata de una reedición de trabajos juveniles, principalmente de la larga introducción que hizo en 1899 al libro de DESMOLINS, Edmundo, ¿En qué consiste la superioridad de los anglosajones?, versión en castellano. Madrid 1899.

10 LYTTLETON, N. A. O., "El patronazgo en la Italia de Giolitti (1892-1924)" en Revista de Occidente, núm. IXX octubre 1973, págs. 94-117.

"VAuSSARD, Maurice, Historia de la Italia contemporánea. Barcelona, Surco, 1961, págs. 115-116.
} 
encontraban aún en la época de los «partidos de notables». Efectivamente, las facciones parlamentarias de los grupos liberales y conservadores constituyeron siempre el centro de la autoridad de los partidos; en su interior se desenvolvían las intrigas y las negociaciones en torno a la elección de los dirigentes y la determinación de su política. Las viejas máquinas electorales, constituidas por los whips y sus oficinas centrales, continuaban buscando, examinando y recomendando a los candidatos, recibiendo y manejando los fondos de su organización central y manteniendo las relaciones de éste con los dirigentes locales ${ }^{12}$. Sin embargo, hay que senalar que estas prácticas caciquiles ni mucho menos son comparables a las utilizadas en otros países del Sur de Europa y que, a diferencia de España, los partidos ingleses ni recurren al "encasillado" ni acuerdan previamente los resultados electorales para imponer el "turnismo".

B) En nuestro país, durante la Restauración, nunca llegó a funcionar un sistema de partidos en sentido moderno. La evolución de los partidos está directamente relacionada con la transición de un régimen liberal a uno democrático, que a su vez implica la transformación del partido aristocrático de grupo interno a partido electoral de grupo externo, tal y como Giovani Sartori los denomina ${ }^{13}$. Es decir, el paso de los partidos orientados sólo hacia el Parlamento, a los partidos de masas dirigidos hacia el conjunto de la sociedad.

En Europa, con la obtención del sufragio universal se consolidan los partidos modernos de masas y se estructura un sistema democrático de partidos. Si bien, esto no se produjo de forma inmediata, pues los partidos de cuadros europeos, herederos de los regímenes electorales censitarios del siglo $\mathrm{xIX}$, en un primer momento trataron simplemente de flexibilizar su estructura, simulando abrirse a las masas. El sistema del caucus de Birmingham en el partido liberal inglés, la Primrose League en el partido conservador y las primarias norteamericanas, corresponden a esta primera fase. En los dos primeros casos se estaba cerca de un partido de masas, existía un sistema de adhesión formal, al mismo tiempo que una cotización regular, pero la vida real del partido se desenvolvía fuera de sus miembros. La Primrose League, fundada por Churchill (padre del célebre Winston) en 1883, se trataba de una organización de simpatizantes que no se inmiscuían en los asuntos del partido. En los primeros años, su estructura era similar a la masonería y su acción política se parecía más a un juego

12 BeER, Samuel H., "La Gran Bretaña: desde un gobierno de minorías hasta la organización de partidos de masas", en la obra de Neuman, Sigmund, Partidos politicos modernos. Madrid, Tecnos, 1965, pág. 40

${ }^{3}$ Sartori, Giovani, Partidos y sistemas de partidos, Madrid, Alianza, 1980, pág. 47. 
de sociedad; sin embargo, a partir de 1900 abandona su elitismo y adquiere un indudable éxito en las regiones rurales donde su movilización a través de manifestaciones sociales (fiestas, proyecciones de linternas mágicas, excursiones...) facilitaba la integración social y animaba al voto conservador ${ }^{14}$. El caucus liberal, con sus secciones de barrio, prefiguraba un verdadero partido de masas, aunque no constituyó más que una experiencia transitoria ${ }^{15}$. En Inglaterra, más que el sufragio universal lo que de verdad impulsó la aparición de los partidos de masas fue la irrupción en el Parlamento, a partir de 1906, del partido laborista que, con casi un millón de afiliados, forzó al resto de los partidos a cambiar sus estructuras.

En Italia, los partidos de masas sólo comenzaron a tener trascendencia con el ascenso electoral del partido socialista y con la creación, en 1919, del partido popular, que comenzará a organizar políticamente a las masas católicas, desempeñando en el futuro un papel importantísimo. En 1919, Francesco Nitti, entonces Presidente del Consejo, cediendo al deseo de los socialistas y de los "populares", hizo votar una nueva ley electoral que instituía el voto proporcional sobre la base provincial. Así, en las elecciones de ese mismo año el éxito de los "partidos de masas" sobrepasó todas las previsiones: hubo 156 diputados socialistas y 99 populares, a costa, sobre todo, de los liberales escindidos en demócratas de Nitti y radicales "giolittistas" ${ }^{16}$.

En España, sin embargo, este proceso no se da; en modo alguno aparecen partidos que agrupen o encuadren grandes multitudes, sino que perviven, durante todo el reinado de Alfonso XIII, partidos llamados de "comités de notables" y modernamente de "Cuadros". Los partidos dinásticos, respecto a su organización interna, no eran otra cosa que agrupaciones de clientelas personales a las que la ideología les importaba poco y en su mayoría estaban compuestos por organizaciones locales independientes, vinculadas a un cacique o jefe local del partido. Hasta llegar al cacique de caciques que era el jefe del partido "porque el gobierno se concedía al señor de señores que había conseguido reclutar el apoyo de mayor número de caciques-jefes de facción" ${ }^{17}$.

En cuanto a su origen social, la mayoría de los políticos españoles de la Restauración fueron hombres nacidos en la clase media, hechos a sí

14 Pombeni, Paolo, Introductión à l'histoire des partis politiques, París, PUF, 1992.

15 Duverger, Maurice, Los partidos políticos. México, FCE, 1984, págs. 95-96.

16 Vaussard, Maurice, Op. cit., págs. 184-190.

17 Varela Ortega, José, Los amigos políticos. Partidos, elecciones y caciquismo en la Restauración (1875-1900). Madrid, Alianza Universidad, 1977, págs. 357-358. 
mismos a través del foro, la prensa o la administración. Sin embargo, esto no quiere decir que hombres pertenecientes a las oligarquías del poder económico no participen directamente del ejercicio del poder político, ni que la escasa importancia de la nobleza en la élite parlamentaria significara que ésta hubiera perdido su prestigio social (lo ejercía por otros medios, por ejemplo, a través de la propia persona del Rey), ni que la vinculación entre poder político y económico no existiera. Más bien sucede, respecto a esto último, todo lo contrario: lo más frecuente es que los representantes políticos figuren en las listas de los mayores contribuyentes y que muchos de los políticos de origen modesto se enriquecieran o ennoblecieran a lo largo de su carrera ${ }^{18}$. De todas maneras, y esto es quizá lo más importante, los políticos de los partidos dinásticos, sea cual fuera su origen, en el orden ideológico compartían los valores del Estado liberal y los usos político-sociales de la Restauración ${ }^{19}$.

En el transcurso de los años la élite parlamentaria fue variando, aunque no sustancialmente. Durante los años 1907 a 1910 se produce una importante renovación del Congreso: 124 nuevos diputados son elegidos en 1907 y 132 firman por primera vez su acta en las elecciones de $1910^{20}$; además, en estas dos elecciones aumenta considerablemente el número de abogados, periodistas y escritores que son elegidos diputados (ver cuadro 1). Incluso, parece que en 1910 hubo un acuerdo entre Canalejas y Romanones al objeto de ufacilitar el triunfo de todas las candidaturas de periodistas que se presentasen en las elecciones para diputados a Cortes y asi entraron en el Parlamento unos 50 periodistas de opuestas etiquetas políticas" ${ }^{21}$. En los años siguientes, numerosos periodistas continuaron obteniendo su acta de diputados, aunque esto no quiere decir que se renovara el Congreso con nuevos aires de libertad, pues la mayoría de ellos «ni conocen los distritos, ni son conocidos en ellos, reciben un acta de los Gobiernos como un verdadero regalo, a cambio de una benevolencia en los juicios, de la cual resulta que el pueblo no conoce jamás la verdadera situación de la política y de sus hombres" ${ }^{22}$. Por otra parte,

18 TUSELL, J., Op. cit., págs. 25-26. En el proceso de acumulación capitalista y creación de nuevas empresas durante los años 1914-1920, numerosos políticos acceden a los Consejos de Administración de las grandes compañías. A este respecto, son muy indicativos los trabajos desarrollados por RoLDÁN, Santiago y GARCía DELGADO, José Luis en La formación de la sociedad capitalista en España (1914-1920). Madrid, CECA, 1973, t. II, págs. 368-444.

19 TUNÓN DE LARA, Manuel, Historia y realidad del poder. El poder y las elites en el primer tercio de la España del siglo XX, Madrid, Edicusa, 1975, págs. 26-27.

20 Sánchez de los SAntos, Modesto, Las Cortes Españolas: las de 1910. Madrid, A. Marzo, 1920, pág. 920.

21 El Universo, 11 de marzo de 1911, citado por Ramos Olivelra, Antonio en Historia de España, t. II. México, Cía Gral. de Ediciones, 1954.

${ }^{22}$ El Año Político, 9 de abril 1916, comentario recogido de la revista España. 
el Senado continuó invariablemente representando los intereses más oligárquicos del país y estando compuesto en un alto porcentaje por miembros de la nobleza (ver cuadro 2).

\section{CUADRO 1}

Clasificación por profesiones de los diputados elegidos en las elecciones de 1907 y 1910

\begin{tabular}{|c|c|c|}
\hline & 1907 & 1910 \\
\hline Abogados & 159 & 222 \\
\hline Ingenieros .. & 20 & 16 \\
\hline Propietarios $\ldots \ldots \ldots$. & 15 & 9 \\
\hline Periodistas y escritores & 15 & 33 \\
\hline Militares $\ldots \ldots \ldots \ldots \ldots \ldots$ & 16 & 16 \\
\hline Banqueros $\ldots \ldots \ldots \ldots \ldots$ & 6 & 7 \\
\hline 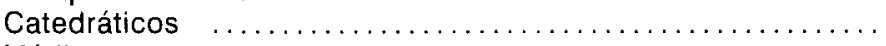 & 19 & 9 \\
\hline 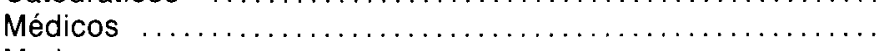 & 5 & 8 \\
\hline 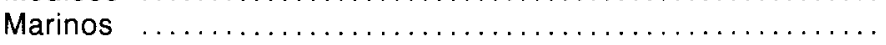 & 5 & 2 \\
\hline Industriales. & 4 & 8 \\
\hline 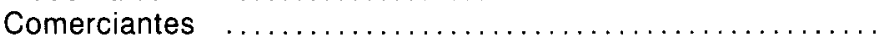 & 3 & 3 \\
\hline 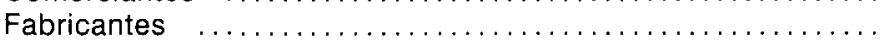 & 2 & 1 \\
\hline Agricultores & 2 & 3 \\
\hline Capitalistas & 2 & 2 \\
\hline Arquitecto $\ldots \ldots \ldots \ldots$ & 1 & 1 \\
\hline Licenciado en Ciencias & 1 & 1 \\
\hline Licenciado en Filosofía ............. & 1 & 1 \\
\hline Notarios $\ldots \ldots \ldots \ldots \ldots \ldots \ldots \ldots \ldots \ldots \ldots \ldots \ldots \ldots \ldots$ & 1 & 2 \\
\hline 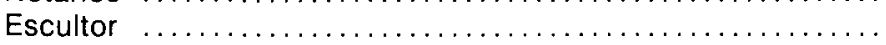 & 1 & - \\
\hline Procuradores & - & 2 \\
\hline 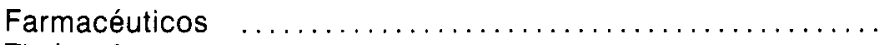 & - & 2 \\
\hline \multirow[t]{2}{*}{ 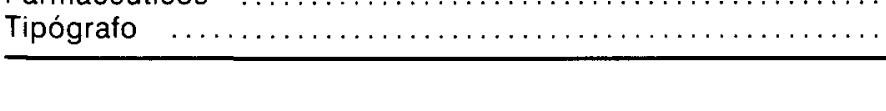 } & - & 1 \\
\hline & 278 & 349 \\
\hline
\end{tabular}

Fuente: SÁnCHEZ de los SANTOS, Modesto, Las Cortes Españolas: Las de 1910. Establecimiento tipográfico de A. Marzo. Madrid 1910, pág. 120. La clasificación sólo es aproximada, pues existen muchos diputados que tienen título académico y no ejercen la carrera y otros que tienen varios títulos. 
CUADRO 2

Influencia de la nobleza en el Senado (año 1910)

\begin{tabular}{lccc}
\hline \multicolumn{2}{c}{ Senadores con título nobiliario } & Total senadores & $\begin{array}{c}\%, \text { nobleza/total } \\
\text { senadores }\end{array}$ \\
\hline Duques $\ldots \ldots \ldots$ & 20 & & \\
Marqueses $\ldots \ldots$ & 52 & & \\
Condes $\ldots \ldots \ldots$ & 31 & & \\
Vizcondes $\ldots \ldots$ & 1 & & \\
Barones $\ldots \ldots \ldots$ & 4 & 359 & 30,08 \\
\hline Total $\ldots \ldots \ldots .$. & 108 & $\ldots$ & \\
\hline
\end{tabular}

Fuente: SánChez de los SANTos, Las Cortes Españolas: Las de 1910. Madrid 1910, pág. 313.

CUADRO 3

Relación de parentesco de alguno de los diputados elegidos en 1916

Eugenio Montero Villegas, hijo de

Avelino Montero Villegas, hijo de

Eduardo Vicenti, yerno de

Manuel Gullón, sobrino de

M. Sáiz de Vicuña, yerno de

Un Sr. Pidal (distrito de Almendralejo), parien-

te (inijo?) de

Alfonso Pidal, pariente de

Alejandro Mon, pariente de

César de la Mora, hijastro de

Conde de Gamazo, hijo de

Conde del Moral de Calatrava, consuegro de

Gabriel Maura, hijo de

Miguel Maura, hijo de

Bernardo M. Sagasta, sobrino de

Ángel Galarza, sobrino de

Eduardo Gasset, hermano de

Ricardo Gasset, hijo de

Eduardo Ortega y Gasset, sobrino de ........

Vicente Ruiz Valarino, hijo de

Manuel Ruiz Valarino, hijo de

Miguel Salvador, hijo de

Amós Salvador, hijo de

Valeriano Weyler, hijo del

Fernando Weyler, hijo del

Heliodoro Suárez Inclán, hermano de

Pío Suárez Inclán, hijo de
Montero Ríos

Garcia Prieto

Alejandro Pidal

Gamazo

Antonio Maura

Sagasta

Rafael Gasset

Ruiz Capdepón, antiguo ministro sagastino

Amós Salvador

General Weyler

Suárez Inclán 
Pedro R. de la Borbolla, hijo de

Francisco del Castillo, yerno de

Duque de Pastrana, yerno de

Marqués de Villabrágima, hijo de

F. López Monis, hijo de

Jorge Silvela, hijo de

Santos Arias de Miranda, hijo de

Antonio María Fabié, hijo de

Juan Navarro Reverter y Gomis, hijo de

Eugenio Barroso, hijo de

Martín Rosales, pariente de

Joaquín Urzáiz, hijo de

M. Alonso Bayón, hijo de

Isidoro Rodrigáñez, hijo de

Conde de Peña Ramiro, hijo de

Eduardo Cobián, hijo de

Fabio Bergamín, hijo de

Joaquín Codorniu, cuñado de

Fermín Loriga, sobrino de

R. Fernández Villaverde, hijo de

Wenceslao Delgado, sobrino de

Francisco de Federico, hijo de

Gregorio Eguilior, hijo de

Cristino Martos, hijo de

Manuel Requejo, hijo de

Villanueva, hijo de

Maraver, sobrino del
Borbolla

Conde de Romanones

I López Muñoz

I Francisco Silvela

I Diego Arias de Miranda

I Fabié

Navarro Reverter

Antonio Barroso, pariente de Sánchez Guerra

Vega Armijo

Angel Urzáiz

Alonso Castrillo

Tirso Rodrigáñez, sobrino de

Sagasta y de la familia de Sán-

chez Guerra

Peña Ramiro, antiguo ministro conservador

| Cobián

I Bergamín

La Cierva

Calbetón

Villaverde

Eleuterio Delgado, antiguo ministro liberal

Federico, antiguo ministro liberal

Eguilior, antiguo ministro conservador

I Martos

Federico Requejo, que ha desempeñado altos cargos

I Villanueva

I General Luque

Fuente: El Año Político, 9 de abril 1916, págs. 92-93. 
Las familias políticas fueron ensanchándose, e hijos, sobrinos, yernos, etc., de los antiguos políticos, ocupaban los más altos puestos en la Administración y en la política. Comentando las elecciones de abril de 1916 , El Año Político recoge un artículo de la revista España, que bajo el título "El nepotismo en el Congreso", califica a la nueva Cámara como "congreso de familia», denuncia a España como el Estado nepótico por excelencia y termina con una clasificación de los 54 diputados vinculados a la política por parentesco (ver cuadro 3). En 1923, unos 120 diputados y senadores pertenecían a las familias de algún ex-ministro. Así resultaba que, por ejemplo, Romanones tenía en las Cortes a tres hijos, un yerno $y$ tres sobrinos y Maura a un hijo, un yerno y dos sobrinos ${ }^{23}$.

El turno pacífico, que comenzó siendo una maniobra para pacificar la vida política, acabar con los mecanismos de rebelión militar tradicionales en el siglo xIX y propiciar sin violencias el proyecto reformista-liberal (enunciado en 1885), se convirtió rápidamente en un sistema oligárquico y caciquil que encorsetó la vida política española. Enseguida mostró su verdadero rostro, el de un pacto entre la monarquía y la gran burguesía agraria y financiera, representada por los partidos liberal y conservador, dos grandes agrupaciones, pero un sólo movimiento político: «una oligarquía absoluta, que tenía, como Jano, dos caras» ${ }^{24}$.

Sin llegar al extremo de Costa para quien el régimen político de la Restauración "no era una monarquía parlamentaria y menos una democracia, sino un absolutismo oligárquico en el puro concepto de Aristóteles» ${ }^{25}$, sí podemos advertir que el sistema político y social vigente en la España del primer tercio del siglo xx nunca llegó a alcanzar la democracia, pues aunque, sobre el papel, desde 1890 España se convirtió en una de las monarquías más avanzadas de Europa, en la práctica, el caciquismo y el bipartidismo oligárquico bastardearon las conquistas liberales del gobierno Sagasta: el juicio por jurado, la ley de asociaciones y, sobre todo, el sufragio universal masculino.

El sistema de la Restauración estaba sustentado en una evidente contradicción: la superestructura política presentaba formas aparentemente avanzadas y progresistas que convivían con una infraestructura atrasada, tradicional, oligárquica y caciquil. Era, sin duda, una situación transicional que sólo se resolvería en una democracia con movilidad política generalizada ${ }^{26}$. Sin embargo, este cambio no se produjo por la evolución in-

\footnotetext{
23 Tusell, J., Op. cit, pág. 28.

24 Ramos Oliveira, A., Historia de España, t. II. México, 1979, pág. 36

25 Costa, Joaquín, Op. cit, pág. 36.

26 Tusell, J., Op. cit., pág. 29.
} 
terna del sistema, ni con la benevolencia de los partidos dinásticos que, salvo excepciones, hicieron todo lo posible por mantener los privilegios del turno e impedir la participación de nuevas fuerzas políticas y sociales.

Me propongo, a continuación, analizar el papel que los distintos grupos liberales tuvieron durante el reinado de Alfonso XIII en la gestación de una triple crisis de orden político: crisis del régimen de participación, del consenso sobre el cual el régimen descansaba y del sistema de partidos.

\section{LOS LIBERALES Y EL SISTEMA ELECTORAL}

El régimen de participación experimentó con el paso del tiempo su propia inviabilidad a medida que fue creciendo y desarrollándose una España real. El crecimiento económico, producido esencialmente a partir de 1914, el aumento demográfico, el crecimiento de la población activa en la industria y, sobre todo, el incremento de la población urbana, en detrimento de la rural ${ }^{27}$, van a cambiar la sociedad española. Esto supondrá un duro golpe al caciquismo, haciéndose cada vez más evidente el fraude electoral y teniendo los partidos dinásticos mayores dificultades para controlar las elecciones en las zonas industriales y urbanas. Durante las primeras décadas del siglo xx, este sistema de representación caciquil comenzó a evolucionar en las grandes ciudades hacia una democracia electoral más genuina y directa; pero en gran parte del campo, la manipulación y el control electoral perduró en mayor o menor grado hasta el derrocamiento del sistema parlamentario ${ }^{28}$.

Aunque existía una conciencia crítica generalizada contra el encasillado $y$ el resto de los procedimientos electorales fraudulentos, compartida incluso por destacados dirigentes liberales o conservadores ${ }^{29}$, lo cierto es que durante todo el tiempo que duró el régimen constitucional este sistema no experimentó cambios importantes y los partidos continuaron utilizándolo e incluso potenciándolo hasta las últimas elecciones de 1923.

Es conveniente señalar que las pequeñas modificaciones que sufrió el encasillado no provenían de interés democratizador alguno, sino que estaban directamente relacionadas con la crisis de la Restauración. Durante los primeros años, en la organización de las elecciones participaban esen-

27 SÁNCHEZ JIMÉNEZ, J., “La población, el campo y las ciudades" en Historia de España $t$. XXXVII, Los comienzos del siglo XX. Madrid, Espasa Calpe, 1984. pags. 130-131.

${ }_{28}$ Tusell, J., Op. cit., pág. 11.

29 Alba, Santiago, Problemas de España, págs. 112-113, Romanones, conde de, “Biología de los partidos", en Obras completas, t. II, págs. 260-261. 
cialmente las direcciones de los partidos liberal y conservador y sólo, excepcionalmente, el pacto se extendía a otras fuerzas políticas con especial incidencia en determinadas circunscripciones. Pero cuando se produce la descomposición del sistema de partidos y éstos se fragmentan, el llegar a un acuerdo electoral entre varios grupos y tendencias complica extraordinariamente el procedimiento, introduciéndose además un factor nuevo: el grupo en el gobierno, ya sea liberal o conservador, utiliza el encasillado contra las otras facciones de su mismo partido buscando alianzas insospechadas, a veces "contra natura", y haciendo de la preparación de las elecciones algo verdaderamente difícil ${ }^{30}$.

El problema es especialmente grave en el caso del partido liberal, que muestra una capacidad de división mayor y más traumática que la del conservador. Ya en las elecciones que el gobierno Moret trató de "organizar" en 1909, se planteó el problema de qué hacer con los grupos liberales existentes dentro del partido. Como se sabe, al final, estas elecciones no llegaron a celebrarse, pero en las que en 1910 presidió Canalejas, el problema de las facciones en el liberalismo volvió a surgir.

Las elecciones de 1914, preparadas desde un gobierno conservador idóneo, fueron clara expresión de las recientes escisiones producidas en los dos partidos dinásticos. Ante el anuncio de convocatoria electoral, los liberales se aprestaron a organizarse y a buscar alianzas para preparar el encasillado y salir lo mejor parados de unas elecciones que inevitablemente servirán para medir las fuerzas de romanonistas y demócratas. Romanones buscó y encontró el acuerdo con Sánchez Guerra, ministro de la Gobernación, y García Prieto no pudo hacer otra cosa que denunciar el boicot electoral a que se le sometía e intentar la alianza con el pequeño grupo reformista liderado por Melquiades Álvarez. En las filas del conservadurismo la situación no fue muy diferente, pues la beligerancia del gobierno idóneo con los mauristas hizo que éstos tuvieran que presentar, tanto en Madrid como en toda España, candidatos propios.

Estas elecciones se distinguieron además por la extrema violencia, la compra de votos y la excesiva intervención gubernamental. Su resultado fue fiel reflejo de cómo se habían preparado: los conservadores-iNóneos, lógicamente, alcanzaron la mayoría absoluta y, de entre los liberales, los romanonistas triplicaron los resultados de los demócratas, aumentando la diferencia de diputados con respecto a lo que ambos grupos tenían en 1913 cuando se produjo la escisión ${ }^{31}$.

\footnotetext{
30 Marin ARCE, José María, Santiago Alba y la crisis de la Restauración. Madrid, UNED, 1990. págs. $75,76,103,209$ y 210

${ }^{31}$ En el Archivo Alba se encuentra una documentación muy interesante sobre la posición de los distintos grupos liberales en los procesos electorales de 1914 a 1923.
} 
Por el contrario, las elecciones de 1916, celebradas bajo el gobierno presidido por Romanones y con el apoyo de los demócratas, se desarrollaron, en términos generales, con un gran acuerdo entre las distintas facciones liberales. En la mayoría de las circunscripciones se confeccionaron listas unitarias y Alba, ministro de la Gobernación, guardó una respetuosa neutralidad entre Romanones y García Prieto. Con otras fuerzas políticas no hubo demasiados problemas a la hora de elaborar el encasillado, claro es que estas elecciones tuvieron como objetivo esencial aislar a la Lliga e impulsar las candidaturas de la unión monárquica en Cataluña y ésto no tenía por qué causar problemas con el resto de los partidos de ámbito nacional.

Las elecciones de 1918 son el ejemplo más evidente de las dificultades para elaborar el encasillado y de la agudización de los conflictos electorales. Dos factores inciden de manera especial en esta confrontación electoral: a) el que las relaciones entre los grupos liberales habian entrado en su punto más bajo tras el triple fraccionamiento de 1917, quedando descartada de antemano cualquier posibilidad de pacto liberal, y b) que García Prieto preside un Gabinete con ministros de muy variada ideología, que intervendrán decisivamente en la confección del encasillado, sobre todo La Cierva, ministro de la Guerra, y el regionalista Ventosa, ministro de Hacienda.

Tanto Alba como Romanones temían que unas elecciones convocadas por un gobierno de coalición, integrado esencialmente por demócratas, conservadores, regionalistas y con un teórico independiente como ministro de la Gobernación, conformaría un Parlamento a la medida de estas formaciones, dejando en extrema debilidad a sus respectivos grupos. Alba, fuera del gobierno, estaba convencido de ello y Romanones, con una débil representación gubernamental, poco podía hacer para impedirlo. Sin duda alguna, los albistas fueron los más perjudicados, García Prieto les pasó la factura de su reciente separación del grupo demócrata, retirándoles todo apoyo gubernamental para formar parte del encasillado y obligándoles a luchar en numerosas circunscripciones contra las más variopintas alianzas.

A medida que se va acentuando la progresiva decadencia del sistema del turno, el encasillado será cada vez más difícil de elaborar, tanto por el deseo del grupo en el poder de obtener una mayoría electoral como por la negativa de los restantes a aceptarla. En las elecciones de 1919 la situación no era, desde luego, la más propicia para conseguir el pacto electoral, pues Maura, al frente de un gobierno de adictos a su persona y de marcado matiz derechista, despertó la animadversión del resto de las fuerzas políticas. Los liberales, temerosos de que Maura rompiera el 
bipartidismo en su propio beneficio, se aliaron con socialistas, republicanos y reformistas en el llamado "bloque de las izquierdas", y los idóneos, intuyendo que Maura pretendía con las elecciones reconstituir bajo su propia jefatura el partido conservador, no dudaron en establecer contactos y acuerdos con otras fuerzas políticas para luchar contra los candidatos mauristas.

Las intenciones del Gobierno se vieron frustradas por los resultados obtenidos en las elecciones celebradas el 1 de junio de 1919, ya que los gubernamentales no lograron ni mucho menos la mayoría y Maura, al poco tiempo, tuvo que dimitir en beneficio del partido conservador. En el liberalismo, estas elecciones suponen el pleno reconocimiento y consolidación de las distintas fracciones, destacándose como verdaderos grupos parlamentarios los ligados al marqués de Alhucemas, al conde de Romanones y a Santiago Alba, mientras que los diputados encabezados por Gasset y Alcalá Zamora, apenas si tuvieron relevancia.

Las elecciones de 1920 tuvieron características muy diferentes a las del año anterior. En esta ocasión los liberales no temían que el gobierno Dato rompiera el "turno", ya que su objetivo político no era conseguir la victoria electoral a costa de los diputados liberales sino más bien a costa de mauristas y ciervistas que eran quienes le impedían tener una mayoría conservadora homogénea para gobernar. Así pues, los liberales no tuvieron que buscar una unidad forzada ni aliarse con republicanos y socialistas y las elecciones se desarrollaron en un clima de relativa calma, de pacto electoral entre la mayoría de los partidos monárquicos y $\sin$ demasiados problemas para elaborar el encasillado.

Quedaba demostrado que cuando no había graves problemas entre las distintas facciones de los partidos dinásticos, derivados en su mayoría de recientes escisiones, y cuando el partido en el gobierno no quería utilizar las elecciones en beneficio propio o aplastar a alguna de las tendencias de su partido, la confrontación electoral se desarrollaba con cierta normalidad. En realidad, los partidos que no formaban parte del "turno" poco o nada pintaban en la organización electoral y los mecanismos caciquiles y oligárquicos permanecieron incólumes hasta la Dictadura. Sólo la masiva abstención, la pérdida progresiva de influencia en los núcleos urbanos de liberales y conservadores y el rechazo a la manipulación electoral fueron índices de la falta total y absoluta de credibilidad en el sistema de representación.

La llegada al poder de la concentración liberal, en diciembre de 1922 , pudo significar una cierta renovación del sistema, pero muy pronto se vieron frustradas esas esperanzas. Su espíritu aparentemente reformador, su programa político, que entre otras cosas incluía la reforma del Senado, 
y el acuerdo con el partido reformista, hasta ahora firme combatiente del caciquismo, no cambiaron en absoluto el mecanismo electoral y las elecciones convocadas en 1923 adolecieron de todos los males propios del sistema. Poco tiempo después de alcanzar el gobierno, García Prieto siguió los pasos tradicionales de reemplazar a los alcaldes provinciales con hombres adictos a la concentración liberal. Sólo dos ministros, el reformista Pedregal y el albista Chapaprieta, se opusieron a este procedimiento caciquil, premonitorio de lo que luego serían las elecciones. Más tarde vino el rechazo del Gobierno a la reforma constitucional y los reformistas, aunque retiraron a su ministro, siguieron apoyando a la concentración y participando con el resto de los grupos liberales en la organización de las elecciones.

Cuando la convocatoria electoral era un hecho, los liberales, todos sin excepción, aceptaron el viejo sistema caciquil, tratando por todos los medios de beneficiarse lo más posible del encasillado y así aumentar la representación parlamentaria de sus respectivos grupos. Las posiciones de las distintas facciones liberales fueron en extremo contradictorias: a) por un lado, estimaban que el electorado español vería en su programa electoral, de carácter reformista, una garantía de cambio político y social, b) pero para asegurarse una mayoría parlamentaria liberal que sostuviera al Gobierno, no renunciaron a las manipulaciones típicas del sistema; así, la coacción, el soborno, la compra de votos y la gran cantidad de diputados elegidos por el artículo 29, demostrarían que los procedimientos de la concentración eran exactamente iguales a los de los gobiernos anteriores, y c) los distintos grupos liberales en vez de presentarse en listas únicas, representando a la concentración, lo hicieron bajo las siglas de cada una de las facciones, en algunos casos acudiendo varias candidaturas liberales por una sola circunscripción.

Además, entre los distintos jefes del liberalismo se produjeron duros enfrentamientos a la hora de elaborar el encasillado, con acusaciones, muchas veces públicas, entre los candidatos. García Prieto utilizó su cargo de presidente del Gobierno para ampliar su grupo parlamentario y el resto, con excepción de Alba, se vieron en extremo favorecidos por los resultados electorales.

En estas últimas elecciones de la Restauración se patentizó también el fracaso del sistema de representación y el abismo que separaba a la mayoría de los ciudadanos de su clase política. Dos aspectos fueron claramente significativos de esta situación: a) el gran número de abstencionhes (32 por 100) y la gran cantidad de diputados electos por el artículo 29 (146 diputados que habían dejado sin posibilidad de votar al 36 por 100 del electorado) y b) la pérdida del control electoral de importantes 
zonas del país como Bilbao, Madrid o Cataluña, que demostraban que el electorado urbano estaba haciéndose cada vez menos permeable a las prácticas caciquiles y la tendencia progresiva de los liberales a perder influencia en las capitales de provincia, teniéndose que recluir en los distritos rurales.

\section{EL LIBERALISMO FRENTE A LA RUPTURA DEL CONSENSO}

La crisis del consenso sobre el que el régimen descansaba comenzó a producirse, precisamente, porque nunca fue amplio, porque siempre fue un mero acuerdo entre familias, un pacto oligárquico que dejaba fuera a la gran mayoría del país. Toda la filosofía política que alienta la Constitución de 1876 y el sistema del turno estaba pensada para una España de finales del siglo xix y fue incapaz de ir evolucionando hacia un sistema democrático mucho más acorde con los cambios sociales y económicos producidos durante el primer tercio del siglo xx.

Esta ruptura del consenso viene determinada esencialmente por dos cuestiones: la política desarrollada por los partidos del turno y el cerrado sistema bipartidista que impedía a otras formaciones políticas, cada vez más representativas, ocupar el espacio que les correspondía. Me interesa, sobre todo, analizar el comportamiento del liberalismo respecto a estos temas y en qué medida los distintos grupos liberales, o más correctamente sus jefes, van a intentar regenerar el régimen constitucional a partir de una política progresista y democratizar el sistema del turno abriéndose a otros partidos.

Durante los años de la guerra europea, la "política económica» estuvo dirigida fundamentalmente a aumentar la intervención del Estado en la planificación y el control económico para contener la grave crisis de subsistencias, el aumento incontrolado de los precios y el déficit, ya crónico, de la Hacienda Pública. Aunque aparentemente el intervencionismo chocaba con los principios de libertad económica y política del liberalismo, la nueva Europa de los monopolios de finales del siglo xIx hacía necesario, precisamente para preservar la libertad del mercado, que el Estado moderno cumpliera su papel de árbitro y asegurara que todos los individuos, no sólo algunos privilegiados, fuesen capaces de competir efectivamente entre ellos en una sociedad libre ${ }^{32}$. Por tanto, los liberales en nuestro país no tendrán problemas ideológicos en aceptar el intervencionismo del Es-

32 Ruggiero, Guido de, Historia del liberalismo europeo. Madrid, Pegaso, 1944, pág. 370. 
tado, es más, se convertirán en abanderados del mismo, frente a los conservadores.

Hay que advertir que actitudes proteccionistas o librecambistas en muchas ocasiones son simplemente coyunturales, no dependiendo de la ideología de liberales o conservadores que alternativamente las aplican, y que el intervencionismo del Estado en materia económica no siempre respondía a los mismos intereses o tenía la misma finalidad. Alba siempre fue contrario a que la intervención del Estado se produjera con la única finalidad de subvencionar a las grandes compañías en crisis, favorecer la concentración del capital, o proteger mediante aranceles o conciertos económicos especiales la industria catalana. De ahí proviene su oposición a que en 1920 continuaran los anticipos a la prensa, los enfrentamientos con La Cierva en 1921, a raiz de la moratoria del contrato de tabacos y del proyecto de ley de transportes, y con Cambó por la prórroga del arancel y la ley de ordenación bancaria.

En una España como la de la Restauración, donde el Estado cumplía casi exclusivamente el papel de mantener una anacrónica maquinaria administrativo-burocrática y garantizar el orden institucional, donde los exiguos fondos de la Hacienda Pública iban dirigidos mayoritariamente a sufragar los enormes gastos de un ejército anticuado y colonial, la primera medida para que desde el Gobierno se pudiera intervenir eficazmente en el orden económico, modernizando el aparato productivo y redistribuyendo la renta, no era otra que aumentar su capacidad recaudatoria a través de una reforma fiscal de carácter progresista. Este fue el objetivo esencial de Alba durante su paso por el Ministerio de Hacienda en 1916.

El ambicioso proyecto económico-financiero presentado por Alba preveía dos etapas: la primera destinada a recaudar más para la Hacienda a través de una reforma fiscal que gravara a los sectores beneficiados por la guerra europea (a este período corresponden los proyectos de ley de beneficios extraordinarios, los relativos al crédito agrario, el impuesto de plusvalía, la reforma de la ley de inquilinato y la creación del Instituto del Crédito); en la segunda etapa se presentarían los nuevos presupuestos y un conjunto de leyes complementarias, indispensables para la transformación económica de nuestro país.

Una furibunda campaña contra los planes de Alba evitó que las leyes más importantes de su proyecto fueran aprobadas en el Parlamento, siendo los más directos responsables: a) los grupos patronales que más se lucraban con la guerra y que, además, supieron organizar una modélica oposición contra el proyecto de ley de beneficios extraordinarios, atra- 
yéndose a la gran mayoría de la burguesía nacional ${ }^{33}$; b) los grandes terratenientes y clases conservadoras, opuestos radicalmente al proyecto de modificación fiscal de la propiedad (tímida reforma agraria) que Alba había anunciado y que tampoco logró llevar adelante cuando fue, por segunda vez, ministro de Hacienda en 1918; c) el conjunto de la clase política, firmemente aliada con la patronal formando una "plutocracia gobernante", que supeditaba toda la política nacional en lo social y en lo económico a los intereses de la gran burguesía, y d) tampoco podemos eludir la responsabilidad ni del gobierno liberal presidido por Romanones que, salvo honrosas excepciones como Rafael Gasset, puso todas las dificultades posibles a la labor del ministro de Hacienda, ni de los distintos grupos liberales que con sus diputados en el Parlamento hicieron el juego a la campaña obstrucionista promovida por los regionalistas catalanes y vascos.

En el proceso de modernización del Estado, los planes de Alba habrían supuesto una preciosa ocasión para poner al día el aparato productivo español, haciendo una profunda y necesaria reforma económico-social que reconstruyera el consenso perdido entre la clase política y la sociedad civil. Se demostró también «no sólo hasta qué punto resultaban, de hecho, incompatibles los intereses predominantes en el seno del capitalismo español de la época y cualquier objetivo de progresivización o personalización de la carga tributaria, sino también, y ello es especialmente importante, la incapacidad de la clase dirigente española para llevar a cabo aquel tipo de ajustes o reformas que se hacian indispensables, antes que nada, para garantizar la propia continuidad del sistema establecido" ${ }^{34}$.

En cuanto a la "política social" poco varió en nuestro país la llevada a cabo por liberales y conservadores. Ambas agrupaciones se negaban a aceptar la lucha de clases, considerando en la mayoría de las ocasiones los conflictos obreros como mero problema de orden público. Al mismo tiempo reconocian la necesidad de una legislación social y laboral cada vez más avanzada que fuera un freno a la tan temida revolución, siempre presente desde 1917. La intervención del Estado en materia social comienza con la creación en 1883 de la Comisión de Reformas Sociales, impulsada por Moret. Luego vendría la aparición en 1903 del Instituto de Reformas Sociales, la formación del Instituto Nacional de Previsión, en 1908, y por fin el Ministerio de Trabajo, durante el gobierno Dato, en 1920.

\footnotetext{
${ }^{33}$ Roldán, S. y García Delgado, J. L., La formación de la sociedad capitalista en España, pág. 225.

${ }^{34}$ Roldan, S. y Garcia Delgado, J.L., Op. cit., pág. 259.
} 
En el desarrollo de la legislación laboral, que discurre parejo a la evolución de estas instituciones, participan por igual liberales y conservadores: Dato, Moret, Canalejas, Romanones, vizconde de Eza, Chapaprieta, etc. son buena muestra de ello. En 1917, a los pocos meses de la Huelga General, los dos partidos dinásticos, en la Conferencia de Seguros Sociales presidida por el vizconde de Eza, acuerdan un programa común para el desarrollo de los seguros sociales, que durante los años siguientes pondrían en práctica gabinetes de distinto signo ${ }^{35}$.

En otros países europeos la legislación sobre seguros sociales estaba muy avanzada, incluyendo en muchos casos la obligatoriedad de los mismos. En Alemania se comenzó en 1883 introduciendo primero el seguro para el riesgo de enfermedad y después el de accidentes de trabajo, basados en la triple contribución del Estado, empresarios y obreros. Apenas se esbozó, en este país, la idea del seguro obrero, "Bismarck comprendió que existía una base inapreciable para asegurar la paz interior de la nación, para que la industria se desarrollase extraordinariamente y para que se obtuviesen recursos a fin de transformar radicalmente las condiciones sanitarias" ${ }^{36}$.

Lo mismo que con la obra de Bismarck en Alemania sucede con la de Asquith y Lloyd George en Inglaterra en 1911, la de Millerand en Francia en 1912 y la de Luzzatti en Italia. En este último país la obligatoriedad del seguro obrero va unida a la convocatoria del Congreso de Roma de 1908 en el que los más ardientes defensores de la libertad se rindieron a la exigencia de una mayor intervención del Estado en asuntos sociales ${ }^{37}$. Durante estos años, la evolución legislativa de los países europeos caminó bajo las directrices alemanas y se intensificó a partir de la guerra europea.

Romanones comprendió que el conflicto europeo hacía necesaria la intervención del Estado en materia laboral ${ }^{38}$ sirviendo de mediador en las relaciones laborales y propiciando el progreso y mejora de las clases urbanas trabajadoras; pero siempre desde una postura paternalista el gobierno debía escuchar las demandas sociales y actuar en consecuencia.

${ }^{35}$ Conferencia de Seguros Sociales de 1917. Madrid, M. Minuesa, 1917.

${ }^{36}$ Maluquer, J., "Reglamentación del Seguro obligatorio de Retiros Obreros", Conferencia en la Real Academia de Jurisprudencia y Legislación. Madrid, 1921, pág. 5.

${ }^{37}$ Degás, M., Les assurances sociales. París, Dunot, 1924, cit. por Gonzalez Posada, C. en Seguros Sociales. Madrid, 1926, pág. 36.

${ }_{38}$ Desde 1905 a 1914, las experiencias de gobiernos liberales o de inspiración neo-liberal que ocuparon "grandes ministerios" en la mayor parte de los paises europeos, tuvieron en común su preocupación por el reformismo social. ROusselIER, Nicolas, L'Europe des liberaux. Bruxelles, Complexe, 1991, pág. 118. 
Para llegar a un compromiso en materia socio-económica, Romanones habia propuesto ya en 1913 el desarrollo de estos cinco puntos: 1) ley de sindicatos obreros, 2) ley de contratos de trabajo, 3) intervención estatal en servicios públicos, 4) inspección del trabajo y 5) arbitración obligatoria $^{39}$.

En el programa de gobierno de la concentración liberal en 1922, la llamada "cuestión social» quedaba reducida al reconocimiento de las organizaciones obreras y a la libertad de sindicación, no porque los liberales fueran partidos obreros o defendieran los intereses de la clase proletaria, sino porque, igual que los conservadores, la temían y quisieron evitar la revolución social. Para ello, nada mejor que seguir el ejemplo de otros países europeos; como decía García Prieto "si en Francia, en Italia, en Alemania y en Inglaterra principalmente se han visto libres del comunismo y del sindicalismo, ha sido evidentemente por la influencia de la obra social realizada en dichos países» ${ }^{40}$.

Si bien en la represión del movimiento obrero y en los conflictos sociales había una coincidencia de principios entre liberales y conservadores, no es menos cierto que sobre los métodos a emplear y sobre el rigor de los mismos, adoptaron posiciones distintas, incluso dentro de las propias filas del liberalismo y el conservadurismo. Durante la huelga general de 1917, tanto Romanones como García Prieto, sin vacilación alguna, se colocaron al lado del orden y del gobierno. Sin embargo, en 1918, con el gobierno nacional de Maura, fueron los liberales, y muy especialmente Alba, quienes impulsaron la tramitación de una ley de amnistía que afectara a los dirigentes socialistas encarcelados desde agosto del año anterior.

Pocos meses después, a principios de 1919, Romanones no tuvo reparos en utilizar al ejército en los conflictos obreros desencadenados por la huelga de "La Canadiense" y decretar la suspensión de las garantías constitucionales. No obstante, hay que decir, en su descargo, que su gobierno cumplió puntualmente el compromiso de implantar la jornada de ocho horas y que intentó llevar a la práctica la negociación con los sindicatos, reconociendo "que en lo sucesivo había que contar con el sindicalismo y sería temerario y antipolítico tratar de destruirlo» ${ }^{41}$.

\footnotetext{
${ }^{39}$ Romanones, conde de "Las responsabilidades deł Antiguo Régimen", en Obras completas, t. II, págs. $566-567$.

${ }^{40}$ La Libertad, 9 de abril de 1922.

${ }^{41}$ Archivo Romanones, leg. 96, núm. 38, "consecuencias que se desprenden de la huelga de la Canadiense".
} 
Tanto en el gobierno como en la oposición, los liberales trataron de desvincularse de la nefasta política que contra la CNT desplegaron la patronal catalana en connivencia con el ejército, la policía y los gobiernos conservadores, a excepción del presidido por Sánchez Guerra en 1922. Ya Romanones, en 1919, luchó decididamente contra el pistolerismo, nombrando gobernador civil de Barcelona a Carlos Montañés y jefe de policía a Gerardo Doval, dos destacados liberales fuera de toda sospecha de vinculación con las bandas armadas financiadas por los patronos. También, destituyó al tristemente famoso, seudo-policia, Bravo Portillo, trató de poner orden en los servicios noliciales y controlar las actividades de Milans del Bosch, Capitán General de Cataluña, aunque al final tuvo que ceder ante el ejército y dar carta blanca a Milans para que reprimiera a su gusto la huelga de "La Canadiense". Esta misma política fue defendida por el resto de los liberales. En numerosas ocasiones, desde la oposición, los parlamentarios liberales encabezados por Alba alzaron su voz en el Congreso, junto a socialistas y reformistas, pidiendo el levantamiento de las garantías suspendidas o denunciando la represión indiscriminada sobre el movimiento obrero catalán. Durante el gobierno de concentración liberal en 1923 se profundizó en esta política de nombramientos de prestigiosos civiles al frente de las instituciones catalanas de orden público; sin embargo, no fue ésto suficiente para cortar la violencia y el terrorismo $y$ en los pocos meses de gobierno las cifras de muertos, heridos y atentados fueron verdaderamente preocupantes.

Las relaciones del último gobierno liberal con el «Ejército» y con la "glesia" no fueron especialmente buenas. Los primeros roces con el clero surgieron cuando Romanones quiso prohibir la venta de tesoros artísticos en poder de la Iglesia. Luego vino la rotunda oposición de la jerarquía eclesiástica a la reforma del artículo 11 de la Constitución, que hacía referencia a las relaciones Iglesia-Estado y a la libertad religiosa. Con el Ejército los problemas llegaron de inmediato, primero por las gestiones que dirigidas por Alba, ministro de Estado, condujeron al rescate de prisioneros en poder de Abd-el-Krim; después por la política tendente a instaurar en Marruecos un protectorado civil y cuyo primer paso fue el nombramiento de Luis Silvela como Alto Comisario en Marruecos, y finalmente, por el temor de los militares a que el Gobierno liberal resolviera el tema de las "responsabilidades", por el desastre de Annual, declarando culpables, exclusivamente, a los mandos militares.

Hacia 1923 ninguno de los partidos dinásticos había conseguido recomponer el consenso político y social sobre el que se habia sustentado el régimen de la Restauración. De nada servirán los propósitos reformistas recogidos en el programa de gobierno que la concentración liberal presentó en abril de 1922: "el ideario de reformar el régimen de la propiedad 
que el señor Alba viene preconizando, la reforma de la Constitución, que pide el señor Álvarez, la política de reconstrucción agraria que defiende el señor Gasset; todo eso ha anunciado el señor marqués de Alhucemas, que también respaldó la resolución de acabar con la guerra de Marruecos, implantando el régimen de Protectorado Civil, y la necesidad de afirmar la libertad de conciencia y de regularizar, coartando, la suspensión de garantías constitucionales» ${ }^{42}$.

Pero una cosa era el programa de la concentración y otra, muy distinta, la política desarrollada por el gobierno liberal durante 1923. El saneamiento del sistema parlamentario ni siquiera se intentó, la reforma de la Constitución fue rápidamente abandonada cuando el Gobierno temió que la Iglesia influyera en los resultados electorales, las reformas económicas y sociales durmieron el sueño de los justos y el tema de las «responsabilidades" fue sucesivamente postergado. Toda la actividad del Gobierno se centró en la resolución del problema de Marruecos, y Alba, como ministro de Estado, cargó con la responsabilidad de cumplir el programa de la concentración en este asunto.

\section{LOS GRUPOS LIBERALES Y LA DISOLUCIÓN DE LOS PARTIDOS DINÁSTICOS}

Desde la desaparición de los líderes que sostienen el turno pacífico, en los primeros años del reinado de Alfonso XIII comienza un largo proceso de descomposición interna de los partidos dinásticos. Para el duque de Maura y Fernández Almagro es en torno a 1913 cuando «la disolución de los partidos históricos ya estaba consumada" " ${ }^{43}$. Quizá sería más correcto decir que es a partir de ese año cuando se produce un progresivo y lento deterioro del turnismo. Su origen se encontraría en la quiebra interna de los partidos liberal y conservador, fraccionados en numerosos grupos o "familias políticas", y en una ruptura paulatina del consenso alcanzado entre Cánovas y Sagasta, que se iba desintegrando a medida que otras fuerzas políticas, desplazadas del sistema, iban creciendo y reclamando su participación en el poder. Todo ello en una difícil situación internacional, en una coyuntura económica no siempre favorable, con importantes luchas sociales, continuas intromisiones del ejército en la vida política y con el problema de Marruecos siempre latente.

42 Vida Nueva, 8 de noviembre de 1922.

${ }^{43}$ Maura, duque de y Fernández Almagro, M., Por qué cayó Alfonso XIII. Madrid, Ambos Mundos, 1948, págs. 163-165. 
El partido liberal a partir de la muerte de Canalejas entra en un período de descomposición irreversible que, con escasos cambios, perdurará hasta el advenimiento de la Dictadura de Primo de Rivera. En una primera etapa, los jefes históricos del liberalismo, Canalejas, Moret y Montero Ríos, dejan paso a una segunda generación de políticos; pero éstos, representados por Romanones, García Prieto y Alba, en vez de seguir el ejemplo unificador de Canalejas, se empeñan en una lucha personalista por la jefatura del partido que desemboca en la formación de dos facciones: romanonistas y garciprietistas o demócratas. Una segunda fase comienza en 1915 con el advenimiento de un gobierno presidido por romanones que reúne a todos los grupos liberales. En este gabinete, con Alba al frente de la cartera de Hacienda, se abre una extraordinaria oportunidad para unificar al liberalismo en torno a un programa económico de carácter progresista. Ocasión perdida, pues la brutal oposición de los sectores y reaccionarios, junto a la falta de apoyo del partido liberal, frustarían los proyectos de Alba.

Durante un tercer período (1917-1918) tendrá lugar la mayor desmembración habida en el liberalismo. Primero, en junio de 1917, se producirá el llamado "pleito por la jefatura" por el que romanonistas y demócratas rompen definitivamente, consumándose la formación de dos partidos. Después, en noviembre de 1917, Alba se separa del grupo demócrata y forma la izquierda liberal. Aparecen también nuevas facciones liberales dirigidas por Gasset y Alcalá Zamora, haciendo del liberalismo un auténtico marasmo de jefes y grupos.

En todo este proceso de máxima fragmentación del partido liberal, que se extiende de 1915 a 1919, existen diferencias notables que conviene señalar. La ruptura entre Romanones y García Prieto respondió casi exclusivamente a intereses puramente partidistas; puesto que no les separaban cuestiones ideológicas o programáticas importantes, las motivaciones hay que buscarlas en el afán de ambos líderes por hacerse con el control y la jefatura del partido. Sin embargo, la creación de la izquierda liberal no adquirió el mismo planteamiento. Cuando Alba comprendió que los grupos romanonista y demócrata no apoyarían nunca con decisión sus proyectos económicos, optó por crear un nuevo partido que situado a la izquierda del liberalismo pudiera impulsar su programa, tantas veces incumplido por gobiernos liberales. Quiso ser, también, la izquierda liberal una organización que rompiera con los viejos partidos locales «nutridos por la plutocracia, servidores obligados de sus egoismos y de su rutina» ${ }^{44}$, proponiendo una renovación democrática del sistema parlamen-

${ }^{44}$ El liberal, 10 de noviembre de 1917. 
tario, declarando la supremacía del poder civil y del Parlamento, francamente devaluados por el turnismo, y quizá lo más importante buscando la alianza con los grupos republicanos, reformista y socialista, para integrarles en el sistema y así ampliar y regenerar el estrecho marco político de la Restauración. El albismo (como también se conocía a la izquierda liberal), aunque en su composición no se apartaba sustancialmente del resto de los grupos liberales, sí podemos afirmar que marcaba con ellos una diferencia capital: contaba con un programa claramente progresista y con una fuerte voluntad de cambio y superación del caduco sistema de partidos.

Desde mediados de 1919 hasta fines de 1922, los liberales, a pesar de encontrarse extremadamente divididos e incluso enfrentados, trataron de reagruparse. Era necesario, tras el fracaso de los llamados gobiernos de concentración, forjar una alternativa liberal de gobierno lo más reformista posible que evitara el hundimiento del sistema político, incapaz de funcionar ya con normalidad. En este proceso de unidad, los liberales nunca se plantearán la reunificación del partido, para ellos la unión sólo consistía en el pacto entre las distintas facciones liberales, manteniendo las jefaturas de sus respectivos grupos.

El gobierno Maura de abril de 1919, con su política autoritaria y sus tácticas electorales que ponían en peligro el turnismo, sirvió para iniciar este movimiento de unidad liberal. Primero se dio la coincidencia entre las distintas fuerzas de oposición, desde liberales a socialistas, que formaron un frente común contra Maura en lo que se llamó el "bloque de las izquierdas». Posteriormente, y una vez celebradas las elecciones, es cuando tienen lugar los primeros contactos entre los liberales que empiezan a hablar de concentracion, piden el concurso de los reformistas $e$, incluso, esbozan un programa que sirva de base a un futuro gobierno liberal.

Pero también en estos primeros encuentros entre los líderes liberales, a requerimiento de Amós Salvador, se ponen de manifiesto las distintas posturas que tienen sobre la unidad. El concepto patrimonial que del partido poseen Romanones y García Prieto, les hace defender la futura concentración como un mero acuerdo transitorio entre los jefes de las distintas facciones liberales; para ellos el programa es algo secundario y la integración de otras fuerzas la limitan al partido reformista. Alba, por el contrario, concibe la concentración como un proceso que supere las divisiones y, sobre todo, acabe con el viejo estatuto de las jerarquías. Estaría basada, además, en un programa que sustentase la unión; pues la unidad, como ya decía Alba en 1917 «ha de establecerse no sobre las 
personas, sino sobre las ideas y las soluciones de gobierno" ${ }^{45}$ y en una política de alianzas que rechace la idea de revivir el viejo partido liberal, proponiendo como alternativa la formación de una gran coalición que incluya a las fuerzas de izquierda, en especial las reformistas y socialistas.

Esta política de pactos diseñada por Alba, junto a su idea de superar las decrépitas jefaturas en el liberalismo, fue lo que más le diferenció de otros grupos liberales. También pretendió con ello un doble objetivo: a) que la asociación con las extremas izquierdas, especialmente los socialistas, dotara a la Monarquía de mayor estabilidad y b) que ensanchando el campo de influencias del liberalismo hacia la izquierda, el albismo ya no sería el grupo izquierdista del partido liberal sino que serviría de árbitro, junto al reformismo, entre la derecha romanonista y demócrata y la izquierda socialista y republicana. Desde esta perspectiva no es de extrañar que Alba estuviera más interesado en el ensayo del «bloque de las izquierdas" que en una unión de los liberales, todavia ambigua, y en la cual la izquierda liberal, por el momento, no tenía un papel director.

Los primeros pasos de acercamiento de las fuerzas liberales no se produjeron como resultado de su evolución interna, sino como fruto de dos factores exógenos al liberalismo: el primero de ellos, la imperiosa necesidad de una respuesta a la política de Maura y el segundo, el ejemplo que el "bloque de las izquierdas" había dado a los liberales de cómo con un cierto grado de unidad era posible impedir que Maura continuara en el poder.

Precisamente porque los estímulos de unificación se dieron desde fuera del liberalismo, el desarrollo de la unidad iba a ser errático, repitiéndose durante más de tres años el esquema siguiente: cuando se cernía sobre ellos la amenaza de un gobierno conservador autoritario, casi siempre de signo mauro-ciervista, reaccionarían agrupándose; sin embargo, cuando participaban en el poder o el gabinete aún siendo conservador era de signo más liberal, rápidamente se fragmentaban, caminando cada cual por su lado. Un fenómeno semejante se produce en el liberalismo europeo, pues como advierte Ruggiero, «aquel fervor crítico y polémico que anima al partido liberal en vísperas de su conquista del Poder, se atenúa y se apaga después que la conquista se produce. Es mucho más fácil controlar a los otros que a uno mismo. La costumbre de gobernar llega a invadirlo todo; la routine administrativa impide la rapidez en la percepción» ${ }^{46}$.

\footnotetext{
${ }_{45}$ AlBa, Santiago, La Izquierda Liberal. Valladolid 1919, pág. 270.

46 Ruggiero, Guido de, Op. cit., pág. 358.
} 
Al mismo tiempo, los problemas internos de los jefes liberales y los distintos intereses que perseguian hicieron aún más difícil el proceso unitario. Romanones, tendente siempre a establecer acuerdos políticos con Maura, es agriamente criticado por el resto de los liberales que le ven como un aliado infiel y él, por su parte, no demuestra el más mínimo interés en fomentar la concentración, sobre todo desde que García Prieto fue nominado jefe de la misma. En mayo de 1921, Romanones se separa de la concentración, actitud que mantendrá hasta la formación del gabinete liberal en diciembre de 1922.

El marqués de Alhucemas adopta una actitud ciertamente pasiva y aunque no se opone a las iniciativas para revitalizar la unidad, sus intervenciones políticas van más encaminadas a servir de enlace con Romanones que a dirigir la concentración, de la cual teóricamente era su cabeza visible. Por el contrario, Alba y Melquíades Alvarez serán los verdaderos impulsores de la concentración, a quienes se debe la elaboración del programa, la propuesta de una campaña de mítines por toda España para promocionar un gobierno liberal y quienes, a pesar de la ausencia de Romanones, supieron atraer a García Prieto hacia sus posiciones.

En diciembre de 1922, bajo la presidencia del marqués de Alhucemas, quedaba constituido el gobierno de concentración liberal. Formaban parte de este gabinete todas las familias liberales, incluidos los romanonistas, representados por sus jefes de fila y sus más directos lugartenientes. La concentración nació con el propósito de superar los fraccionalismos y convertirse en un partido único y homogéneo, pero los políticos liberalreformistas creyeron que primero debian de obtener el poder para más tarde caminar en ese proyecto. Lo que luego pasó fue que los líderes de la concentración, inmersos en los graves y acuciantes problemas nacionales e incapaces de superar los personalismos, no se dieron cuenta que la construcción de una organización para alzarse con el gobierno no creaba automáticamente un partido político unificado. Sólo Romanones veía con claridad que la concentración no era la simiente de un renovado partido sino una condición temporal de los grupos liberales sin futuro unitario. Tampoco Melquíades Álvarez tuvo nunca la intención de dejar que su partido reformista fuese absorvido por los liberales.

Al fracaso de constituir un nuevo partido liberal se sumó el angustioso problema de Marruecos, las profundas divergencias surgidas entre los distintos grupos liberales y la imposibilidad de cumplir el programa de la concentración. En los últimos meses de su mandato, el gobierno liberal presentaba el siguiente panorama: Romanones, Presidente del Senado, continuaba sin comprometerse en las labores gubernamentales, Melquiades Álvarez y Alcalá Zamora fuera del gobierno y García Prieto, Presidente 
del Consejo de Ministros, sin la autoridad ni la iniciativa necesarias para ejercer el cargo, dejaba que su ministro de Estado, Santiago Alba, se convirtiera en el auténtico rector del gabinete.

Malogrado el intento de renovación del sistema parlamentario, prácticamente rota la concentración liberal, sin apoyo ninguno el gobierno y sin posibilidad de alternativa conservadora, el vacío de poder era casi absoluto. No es extraño que el golpe militar no encontrara ninguna oposición; más aún, contara con el beneplácito y las esperanzas de gran parte de la opinión pública. No se debe, pues, aceptar la tesis de que el alzamiento militar "asestó el golpe al sistema parlamentario en el momento en que se operaba la transición de la oligarquía a la democracia... No era la primera ni la última vez que un General aseguraba rematar un cuerpo enfermo cuando de hecho, estaba estrangulando a un recién nacido" ${ }^{47}$. Aun suponiendo que algunos liberales, Alba y Melquíades Álvarez, sí pretendieron acabar con el sistema oligárquico tradicional, el conjunto de la concentración liberal no hizo nada por terminar con los viejos hábitos de la política del turno. Así, cuando llegó septiembre de 1923, el gobierno liberal no es que estuviera enfermo, es que ya había muerto. Otra cosa es que el parto de Primo de Rivera fuese un monstruo.

Tras el breve gobierno de concentración liberal, el liberalismo se encontraba tan dividido y roto que a los pocos meses de instaurado el nuevo régimen dictatorial, los distintos grupos conservadores y liberales eran disueltos formalmente por sus respectivos jefes. Ya no se hablará más del partido liberal o del conservador, sólo una débil oposición al Directorio aglutinará, indistintamente, a liberales o conservadores, y líderes como Sánchez Guerra, Burgos y Mazo, Romanones, Melquíades Álvarez o Alba no tendrán el menor inconveniente en luchar juntos por el restablecimiento del régimen constitucional y contra la Dictadura.

En el posicionamiento de liberales y conservadores contra el régimen fueron determinantes las actitudes del Rey; pues a medida que se iban frustrando las esperanzas de que el Monarca prescindiera del Dictador y restaurara el régimen constitucional, la oposición liberal fue radicalizándose y adoptando posiciones cada vez más cercanas al republicanismo. Alfonso XIII, que nunca había pretendido de la Dictadura más que una solución transitoria, en la práctica claudicó ante los planes del marqués de Estella, buscándose la enemistad de quienes más podian haberle ayudado: los antiguos políticos monárquicos que durante seis años se vieron ignorados y despreciados por el Monarca.

47 Carr, R., Op. cit., pág. 505. 